\title{
Tunable function of feeding network and SPDT switch for WIMAX application
}

\author{
N. Edward ${ }^{1}$, N. A. Shairi ${ }^{2}$, Z. Zakaria ${ }^{3}$, T. Sutikno ${ }^{4}$, I. D. Saiful Bahri ${ }^{5}$ \\ 1,2,3,5 Faculty of Electronic and Computer Engineering (FKEKK), Universiti Teknikal Malaysia Melaka (UTeM), Malaysia \\ ${ }^{4}$ Department of Electrical Engineering, Universitas Ahmad Dahlan, Indonesia
}

\begin{tabular}{|c|c|}
\hline Article Info & ABSTRACT \\
\hline Article history: & A tunable circuit that functions as a power divider and a single pole double \\
\hline Received Dec 18, 2018 & $\begin{array}{l}\text { throw (SPDT) switch is proposed in this paper. The power divider design } \\
\text { was based on the conventional Wilkinson power divider (WPD). Since WPD }\end{array}$ \\
\hline Revised Feb 19, 2019 & design has wideband properties, a modification was made in the design to \\
\hline Accepted Mar 5, 2019 & $\begin{array}{l}\text { make it narrowband so that it will only work for WiMAX applications. } \\
\text { Two shorted stubs were introduced in the transmission line of the output }\end{array}$ \\
\hline Keywords: & $\begin{array}{l}\text { ports to encounter the mismatch when the function was switched to an SPDT } \\
\text { switch. Rogers RO4350 (er }=3.48, \mathrm{~h}=0.508 \mathrm{~mm}) \text { was used as a substrate }\end{array}$ \\
\hline Matching stubs & material and copper (thickness $=0.035 \mathrm{~mm}$ ) related to patch of this proposed \\
\hline Power divider & $\begin{array}{l}\text { design. When the circuit functioned as a power divider, the simulated result } \\
\text { showed } S 11<-16 \mathrm{~dB}, \mathrm{~S} 12>3.97 \mathrm{~dB} \text { and } \mathrm{S} 23<-14 \mathrm{~dB} \text { for both operating }\end{array}$ \\
\hline SPDT switch & frequencies of $2.5 \mathrm{GHz}$ and $3.5 \mathrm{GHz}$. On the other hand, when the circuit \\
\hline Tunable function & $\begin{array}{l}\text { functioned as an SPDT switch and port } 2 \text { was in the ON state, the simulated } \\
\text { result showed } \mathrm{S} 11<-35 \mathrm{~dB}, \mathrm{~S} 12>-1.1, \mathrm{~S} 13<-16 \mathrm{~dB} \text {, and } \mathrm{S} 23<18 \mathrm{~dB} \text { for } \\
\text { both operating frequencies of } 2.5 \text { and } 3.5 \mathrm{GHz} \text {. The proposed design showed } \\
\text { a good performance as a power divider and an SPDT switch, thus, it can be } \\
\text { used for multifunctional microwave circuits. }\end{array}$ \\
\hline
\end{tabular}

Copyright @ 2019 Institute of Advanced Engineering and Science. All rights reserved.

Corresponding Author:

Nurhasniza Edward,

Faculty of Electronic \& Computer Engineering.

Universiti Teknikal Malaysia Melaka (UTeM),

Hang Tuah Jaya, 76100 Durian Tunggal, Melaka, Malaysia.

Email: nurhasniza187@gmail.com

\section{INTRODUCTION}

In terms of microwave and millimeter systems applications, power dividers play an important role in power combining and splitting [1]. Power divider can be used to allocate the input power into two different paths with preferred power dividing ratio. Currently, reconfigurable mobile terminals have become trendy. Thus, there are many reconfigurable antennas that have been examined and demonstrated [2]-[4]. In order to support the systems, advanced feeding network is essential [5], [6]. Besides, rapid development in modern wireless communication has resulted in high demand for reconfigurable circuits.

There are many techniques can be done to achieve tunable properties of power dividers. Most of the researches focus on tuning the operating frequency in power divider [7]-[13]. Tuning the power division ratio also become a recent trend for research [14]-[18]. Varactors [8]-[17] and pin diodes [7], [18] are the main component used to achieve tunable functions of the power divider.

Tunable power divider does not mean to tune the operating frequency or power division ratio only, but it also can tune the functions of the power divider. However, there are only a few works available on tunable functions of power divider. In [19]-[21], reconfigurable power dividers that can perform as a power divider or a switch were discussed. In [19], it discussed the reconfigurable power divider based on the concept of modes match and impedance match between substrate integrated waveguide (SIW) and half-mode SIW (HMSIW). However, the size of the circuit was very bulky and it had a complex design. 
Two reconfigurable power dividers based on micro-strip lines were discussed in [20]-[21]. The proposed designs in [20] and [21] can either perform as a power divider or a switch.

In [20], by using the positive and negative group delays, power divider can be tunable between path 2 and 1 for positive group delay (PGD) or path 3 and 1 for negative group delay (NGD). However, there was a trade-off between group delay and bandwidth. Furthermore, in [21], it proposed two designs with different numbers of switches. In the first design, by using three switches, it can re-route the output power between one and two ports. Meanwhile, in the second design, four switches were used and a switched coupled line transformer was employed in the design. However, the reflection coefficient (S11) was not ideal when power was routed from port 1 to port 2.

In this paper, two designs of the modified Wilkinson power divider are presented, which have dual functions that can perform as a power divider or an SPDT switch in a single design by using PIN diode. Two shorted stubs were introduced to encounter the mismatch when the function was changed to the SPDT switch state. Furthermore, this proposed design had a simpler design and showed a good performance for both functions (as a power divider and an SPDT switch), compared to [19] and [21]. In this paper, the tunable functions of feeding network and SPDT switch were designed, simulated and investigated.

\section{RESEARCH METHOD}

\subsection{Wilkinson Power Divider and Design Equation}

In 1960, Ernest Wilkinson proposed the Wilkinson power divider, which gives isolation between ports at the output and is adept to match in all ports. It can also be lossless when the port at the output is matched [22]. Figure 1 shows the equal transmission line circuit for WPD that delivers an equal force to both ports at the output [23].

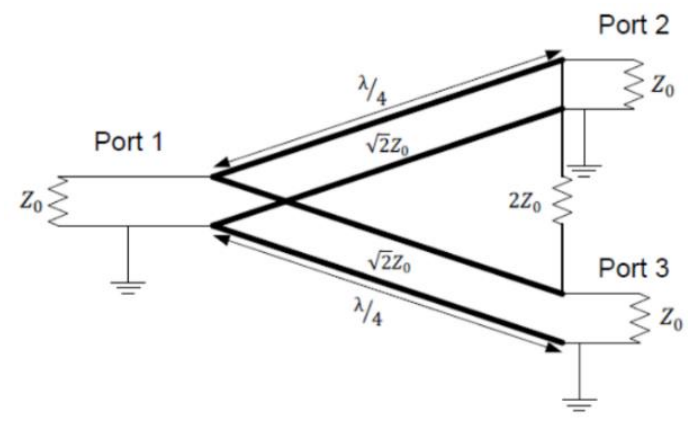

Figure 1. The circuit model of transmission line for WPD [23]

WPD is a three-port network that consists of one input port and two output ports as shown in Figure 1. Generally, the power can be divided equally or unequally at two different working frequencies depending on the application.

Based on the conventional WPD, two WPDs were designed for working frequencies of $2.5 \mathrm{GHz}$ and $3.5 \mathrm{GHz}$. Z0 value of $50 \Omega$ was used in the design. Furthermore, the design also included an isolation resistor with a value of $2 Z 0=100 \Omega$ and an impedance of a quarter-wave section split transmission line with the value of $\sqrt{ } 2 Z 0=70.7 \Omega$. In (1), it shows a perfect scattering matrix (S-matrix) of WPD with a load.

$$
S=\frac{-j}{\sqrt{2}}\left[\begin{array}{lll}
0 & 1 & 1 \\
1 & 0 & 0 \\
1 & 0 & 0
\end{array}\right]
$$

The S-matrix shows that when the signal enters port 2, it will be the same as port 3, as it separates equally into port 2 and 3. Ports that are matched sets (S11, S22, and S33) are equal to zero. The power divider is lossless as the signal enters port 1 . The magnitude, which is the total squares each component of column one of the S-matrix, is equivalent to one [23].

\subsection{The Proposed Design of Modified WPD and SPDT Switch}

By adjusting the voltage biasing, the function of the proposed design can be switched to either a power divider or an SPDT switch. The proposed design is based on the conventional Wilkinson power 
divider. Since the conventional Wilkinson power divider has wideband properties, a modification was made to the design so that it becomes narrowband. Narrowband is required so that it will only allow signals at 2.5 $\mathrm{GHz}$ and $3.5 \mathrm{GHz}$. Since two operating frequencies are required for WiMAX applications, two modified WPDs were designed with matching stub to achieve dual functions. PIN diode is an essential component in order to achieve a tunable function. Figure 2 shows the two configurations of the tunable functions of feeding network and SPDT switch and the position of PIN diodes (D1-D6) for different operating frequencies $(2.5 \mathrm{GHz}$ and $3.5 \mathrm{GHz})$.

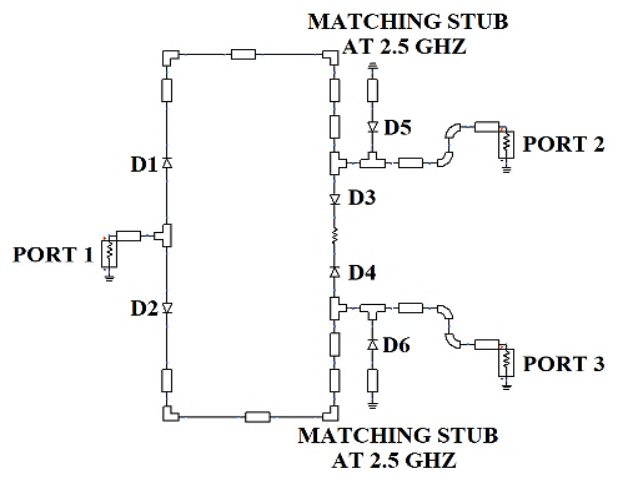

(a)

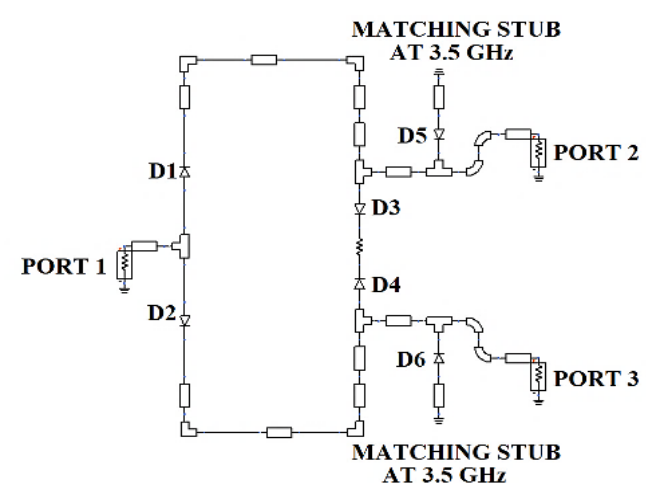

(b)

Figure 2. The proposed design of the tunable function of feeding network and SPDT switch

Figure 3 (a) and (b) show the circuit configuration when the function is in the power divider state for both operating frequencies. In this state, the matching stubs will be turned off. The matching stubs will be used for SPDT switch state only. PIN diode D5 and D6 are the controlling switches for the matching stubs. When the D5 and D6 diodes are turned off and the other switch is turned on, it will operate as a power divider.

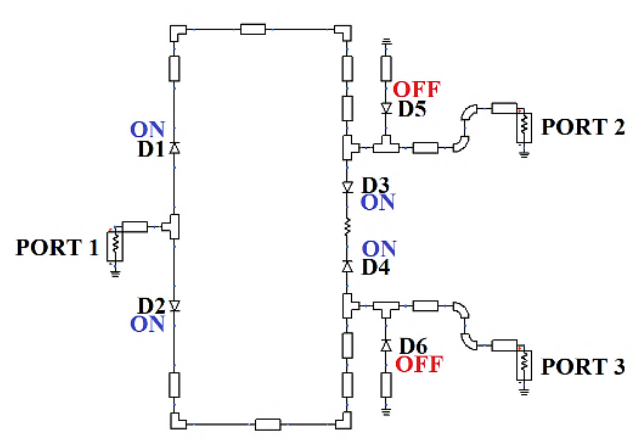

(a)

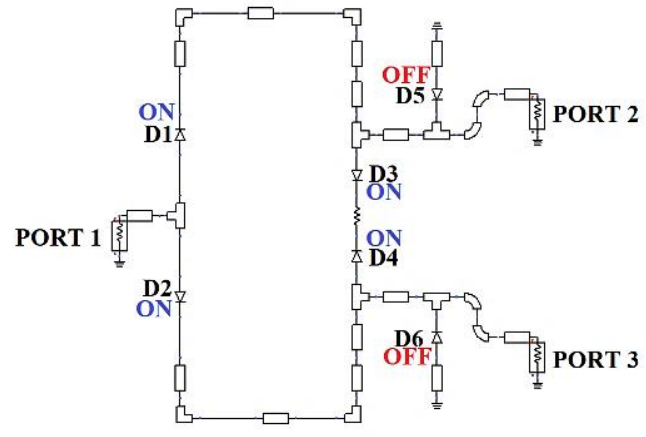

(b)

Figure 3. (a) Circuit configuration of power divider at $2.5 \mathrm{GHz}$ and (b) circuit configuration of power divider at $3.5 \mathrm{GHz}$

Figure 4 (a) and (b) show the circuit configuration when the circuit is in the SPDT switch state at operating frequencies of $2.5 \mathrm{GHz}$ and $3.5 \mathrm{GHz}$, respectively. In this state, only one of the output ports will be switched on and the matching stub connected to the transmission line of the output port will also be switched on to encounter the mismatch. Without the matching stubs, the operating frequency in the SPDT switch state will be shifted. From Figure 4, port 2 will be in the ON state and port 3 will be in the OFF state. In order to turn off port 3, PIN diode D2, D3, D4, and D6 will be switched off. 


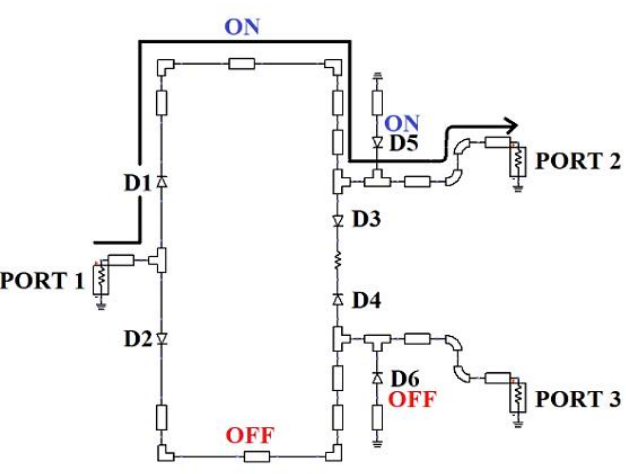

(a)

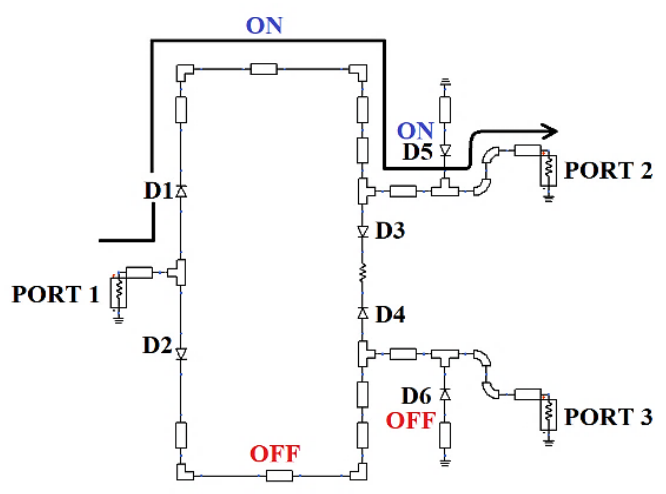

(b)

Figure 4. (a) The circuit configuration for SPDT switch at $2.5 \mathrm{GHz}$ and (b) the circuit configuration for SPDT switch at $3.5 \mathrm{GHz}$

\section{RESULTS AND ANALYSIS}

\subsection{The Proposed Design of Modified WPD}

A parametric study was conducted to make the operating frequency narrowband. It was found that transmission line at the input and output ports played an important role to make the proposed design became narrowband. When the transmission line of the input and output ports were adjusted, the power divider did not have the same impedance value as compared to the conventional WPD, which was at $Z 0=50 \Omega$. For the conventional power divider, the transmission line at the input and output ports had the same dimension. However, for this proposed design, transmission line at port 1 had a different dimension than the transmission line at port 2 and 3. Port 2 and 3 must have an equal dimension of transmission line even after tuning in order to deliver an equal force to both ports at the output.

The proposed power dividers in Figure 2 (a) and (b) were simulated to acquire the results for S11, $\mathrm{S} 12$, S13, and S23. Figure 5 (a) and (b) show the results for S11, S12, S13, and S23 at operating frequencies of $2.5 \mathrm{GHz}$ and $3.5 \mathrm{GHz}$.

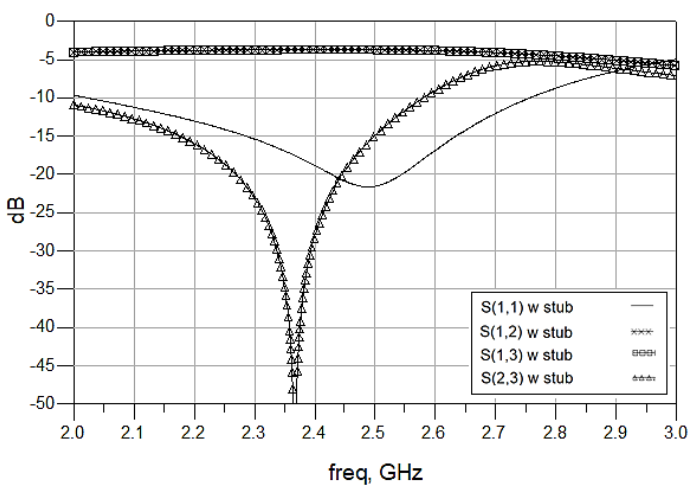

(a)

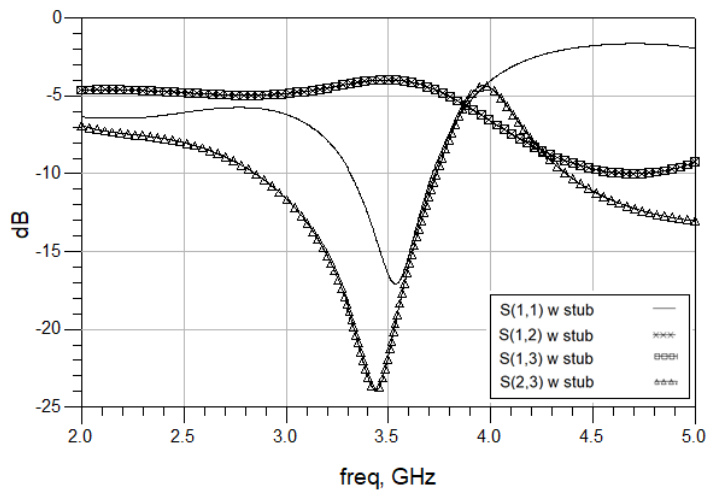

(b)

Figure 5. The results of S11, S12, S13 and S23 for power divider at (a) $2.5 \mathrm{GHz}$ and (b) $3.5 \mathrm{GHz}$

The return loss of the proposed power divider at $2.5 \mathrm{GHz}$ was $21.554 \mathrm{~dB}, \mathrm{~S} 23$ was $-14.968 \mathrm{~dB}, \mathrm{~S} 12$, and S13 was $-3.698 \mathrm{~dB}$. Meanwhile, the return loss of power divider at $3.5 \mathrm{GHz}$ was $16.444 \mathrm{~dB}$, S23 was $21.835 \mathrm{~dB}, \mathrm{~S} 12$ and S13 was $-3.964 \mathrm{~dB}$.

\subsection{The Proposed Design of Modified SPDT Switch}

The PIN diode D5 and D6 played an important role when the state was switched from power divider to SPDT switch. D5 and D6 only turned on for the SPDT switch function because it was connected to the matching stubs that were used to encounter mismatch. 
In order to obtain SPDT switch state, PIN diode D2, D3, D4, and D6 were turned off. This made port 2 to be in the ON state and port 3 in the OFF state. Figure 6 (a) and (b) show the return loss, S11 and insertion loss, S12, S13 for frequencies at $2.5 \mathrm{GHz}$ and $3.5 \mathrm{GHz}$ for SPDT switch, respectively.

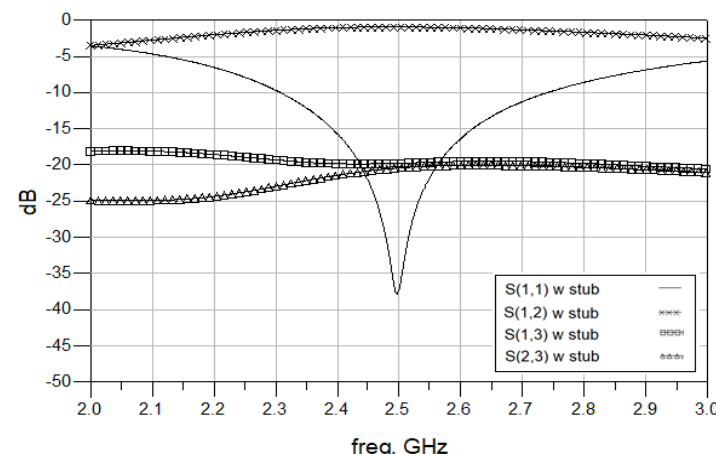

(a)

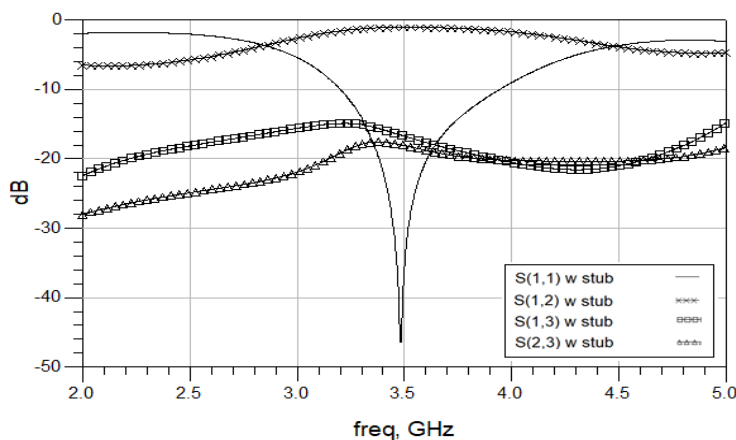

(b)

Figure 6. The results of S11, S12, S13 and S23 for SPDT switch at (a) $2.5 \mathrm{GHz}$ and (b) $3.5 \mathrm{GHz}$

The return loss of the proposed SPDT switch at $2.5 \mathrm{GHz}$ was $37.467 \mathrm{~dB}, \mathrm{~S} 12$ was $-0.924 \mathrm{~dB}, \mathrm{~S} 13$ was $-19.773 \mathrm{~dB}$ and S23 was $-20.429 \mathrm{~dB}$. Meanwhile, the return loss of the SPDT switch at $3.5 \mathrm{GHz}$ was $39.992 \mathrm{~dB}, \mathrm{~S} 12$ was $-1.033 \mathrm{~dB}, \mathrm{~S} 13$ was $-16.712 \mathrm{~dB}$ and S23 was $-18.060 \mathrm{~dB}$.

Table 1 lists the performances of previous works on reconfigurable power dividers based on SIW/HMSIW and microstrip line. From the table, this proposed design has competitive return loss, insertion loss, and even isolation when working as SPDT or power divider. In [19], the design was based on SIW or HMSIW technology. Nevertheless, the design was complex, bulky (in terms of circuit size) and difficult to fabricate. Meanwhile, in [21], the designs were based on microstrip lines and they were simple. However, in [21], the result of the SPDT switch function for S11 was not ideal and it did not include the results for isolation between the output ports. Compared to the previous works [19] and [21], this work had a simpler design. This design only used matching stubs and was able to achieve dual functions. Furthermore, this design also had a good performance compared to others.

Table 1. Comparison of Tunable Function Circuit with Different Technologies

\begin{tabular}{|c|c|c|c|c|c|}
\hline & \multicolumn{2}{|c|}{ This Work } & {$[19]$} & {$[21]$} & \\
\hline Method & \multicolumn{2}{|c|}{$\begin{array}{c}\text { Based on microstrip } \\
\text { lines }\end{array}$} & $\begin{array}{c}\text { Based on siw/hmsiw } \\
\text { technology }\end{array}$ & $\begin{array}{c}\text { Based on microstrip } \\
\text { lines }\end{array}$ & \\
\hline Complexity & \multicolumn{2}{|c|}{ Simple design } & Complex design & Simple design & \\
\hline $\begin{array}{l}\text { Center } \\
\text { Frequency }\end{array}$ & $2.5 \mathrm{Ghz}$ & $3.5 \mathrm{Ghz}$ & $4.95 \mathrm{Ghz}$ & $2.14 \mathrm{Ghz}$ & \\
\hline S11 & -21.554 & -16.444 & 14.5 & $<-20$ & POWER \\
\hline S21 & -3.698 & -3.964 & 4.35 & $>-4$ & DIVIDER (Db) \\
\hline $\mathrm{S} 23$ & -14.968 & -21.835 & $>-7$ & $<-20$ & \\
\hline S11 & -37.467 & -36.992 & -15 & -17 & SPDT \\
\hline $\mathrm{S} 21$ & -0.924 & -1.033 & -1.35 & -0.8 & (PORT 2 IS IN \\
\hline S31 & -19.773 & -16.712 & -23 & $<-20$ & 'ON'STATE) \\
\hline $\mathrm{S} 23$ & -20.429 & -18.060 & -27 & - & $(\mathrm{Db})$ \\
\hline
\end{tabular}

\section{CONCLUSION}

The tunable functions of a feeding network and an SPDT switch for WiMAX application were designed, simulated, and analyzed successfully. Two modified WPDs were designed with matching stubs to achieve dual functions by using PIN diodes. The simulation results for the tunable functions of feeding network and SPDT switch showed good performance for both frequencies at $2.5 \mathrm{GHz}$ and $3.5 \mathrm{GHz}$. In the power divider state, the simulation result for S11 was less than $-16 \mathrm{~dB}, \mathrm{~S} 23$ less than $-14 \mathrm{~dB}$, and $\mathrm{S} 12$ and S13 better than $-3.964 \mathrm{~dB}$. Meanwhile, in the SPDT state, the simulation results showed that the return loss was more than $35 \mathrm{~dB}$, the $\mathrm{S} 12$ was better than $-1.1 \mathrm{~dB}, \mathrm{~S} 13$ was less than $-16 \mathrm{~dB}$, and S23 was less than $-18 \mathrm{~dB}$. 


\section{ACKNOWLEDGEMENTS}

We are grateful to UTeM Zamalah Scheme, Center for Research and Innovation Management (CRIM) and Universiti Teknikal Malaysia Melaka (UTeM) for their encouragement and help in supporting financially to complete this research work.

\section{REFERENCES}

[1] H. Mirzaei, et al., "Arbitrary-angle squintfree beamforming in series-fed antenna arrays using non-Foster elements synthesized by negative group delay networks," IEEE Trans. Antennas and Propagation, vol. 63, no. 5, pp. 1997-2010, May 2015.

[2] A. Ghasemi, et al., "A reconfigurable printed monopole antenna for MIMO application," in 2012 6th European Conference on Antennas and Propagation (EUCAP), Prague, 2012, pp. 1-4.

[3] J. H. Lim, et al., "A Reconfigurable PIFA Using a Switchable PIN-Diode and a Fine-Tuning Varactor for USPCS/WCDMA/m-WiMAX/WLAN," IEEE Transactions on Antennas and Propagation, vol. 58, no.7, pp. 2404-2411, 2010.

[4] A. Khaleghi and M. Kamyab, "Reconfigurable Single Port Antenna with Circular Polarization Diversity" IEEE Transactions on Antennas and Propagation, vol. 57, no. 2, pp. 555-559, 2009.

[5] S. H. Wi, Y. P. Zhang, H. Kim, I. Y. Oh, and J. G. Yook, "Integration of Antenna and Feeding Network for Compact UWB Transceiver Package," IEEE Transactions on Components, Packaging and Manufacturing Technology, vol. 1, no.1, pp. 111-118, 2011.

[6] S. Hebib and H. Aubert, "Triband antenna feeding circuit for circular polarization diversity," in $201141 s t$ European Microwave Conference, Manchester, 2011, pp. 890-893.

[7] W. Zhou, T. Arslan, K. Benkrid, A. O. El-Rayis and N. Haridas, "Reconfigurable feeding network for GSM/GPS/3G/WiFi and global LTE applications," in 2013 IEEE International Symposium on Circuits and Systems (ISCAS2013), Beijing, 2013, pp. 958-961.

[8] H. L. Zhang, Y. J. Guo, T. Gao and B. J. Hu, "Continuously frequency reconfigurable power divider with large tuning bandwidth," in 2015 Asia-Pacific Microwave Conference (APMC), Nanjing, 2015, pp. 1-3.

[9] H. L. Zhang, T. Gao, Y. J. Guo and B. J. Hu, "Frequency reconfigurable Unequal power divider with continuously broad tuning bandwidth," in 2015 Asia-Pacific Microwave Conference (APMC), Nanjing, December 2015, pp. 1-3.

[10] T. Zhang and W. Che, "A Compact Tunable Power Divider With Wide Tuning Frequency Range and Good Reconfigurable Responses," IEEE Transactions on Circuits and Systems II: Express Briefs, vol. 63, no. 11, pp. 1054-1058, November 2016.

[11] T. Zhang, X. Wang and W. Che, "A Varactor Based Frequency-Tunable Power Divider With Unequal Power Dividing Ratio," IEEE Microwave and Wireless Components Letters, vol. 26, no. 8, pp. 589-591, August 2016.

[12] X. Shen, Y. Wu, S. Zhou and Y. Liu, "A Novel Coupled-Line Tunable Wilkinson Power Divider With Perfect Port Match and Isolation in Wide Frequency Tuning Range," IEEE Transactions on Components, Packaging and Manufacturing Technology, vol. 6, no. 6, pp. 917-925, June 2016.

[13] X. Shen, Y. Liu, S. Zhou and Y. Wu, "A novel compact tunable coupled-line power divider using varactors," in 2015 Asia-Pacific Microwave Conference (APMC), Nanjing, December 2015, pp. 1-3.

[14] Y. Ohta, R. Ishikawa and K. Honjo, “A 5.8-GHz reconfigurable power divider for wireless power transfer," in 2014 Asia-Pacific Microwave Conference, Sendai, Japan, November 2014, pp. 693-695.

[15] E. A. Abbas and A. Abbosh, "Millimeter wave tunable power divider using modified Wilkinson design," in 2016 IEEE 2nd Australian Microwave Symposium (AMS), Adelaide, SA, February 2016, pp. 3-4.

[16] L. Guo, H. Zhu and A. M. Abbosh, "Wideband Tunable In-Phase Power Divider Using Three-Line Coupled Structure," IEEE Microwave and Wireless Components Letters, vol. 26, no. 6, pp. 404-406, June 2016.

[17] E. A. Abbas and A. M. Abbosh, "Tunable millimeter-wave power divider for future 5G cellular networks," in 2016 IEEE International Symposium on Antennas and Propagation (APSURSI), Fajardo, July 2016, pp. 1715-1716.

[18] H. Fan, X. Liang, J. Geng, R. Jin and X. Zhou, "Reconfigurable Unequal Power Divider With a High Dividing Ratio," IEEE Microwave and Wireless Components Letters, vol. 25, no. 8, pp. 514-516, August 2015.

[19] H. Chen, W. Che, Y. Cao, W. Feng and K. Sarabandi, "Function-Reconfigurable Between SPDT Switch and Power Divider Based on Switchable HMSIW Unit," IEEE Microwave and Wireless Components Letters, vol.27, no.3, pp. 275-277, 2017.

[20] G. Chaudhary, P. Kim, J. Jeong, and Y. Jeong, "Power divider with tunable positive and negative group delays using parasitic compensated PIN diode," in 2016 IEEE Radio and Wireless Symposium (RWS), Austin, TX, 2016, pp. 4-6.

[21] T. Lehmann, F. Hettstedt and R. Knoechel, "Reconfigurable Wilkinson power dividers with minimum number of switches," Electronics Letters, vol. 45, no. 2, pp. 111-112, Jan. 2009.

[22] E. J. Wilkinson, "An N-Way Hybrid Power Divider," IRE Transactions on Microwave Theory and Techniques, vol. 8, no. 1, pp. 116-118, 1960.

[23] D. Pozar, Microwave Engineering, 3rd ed. Hoboken, New Jersey: John Wiley \& Sons Inc, 2005, pp. 308-361. 


\section{BIOGRAPHIES OF AUTHORS}

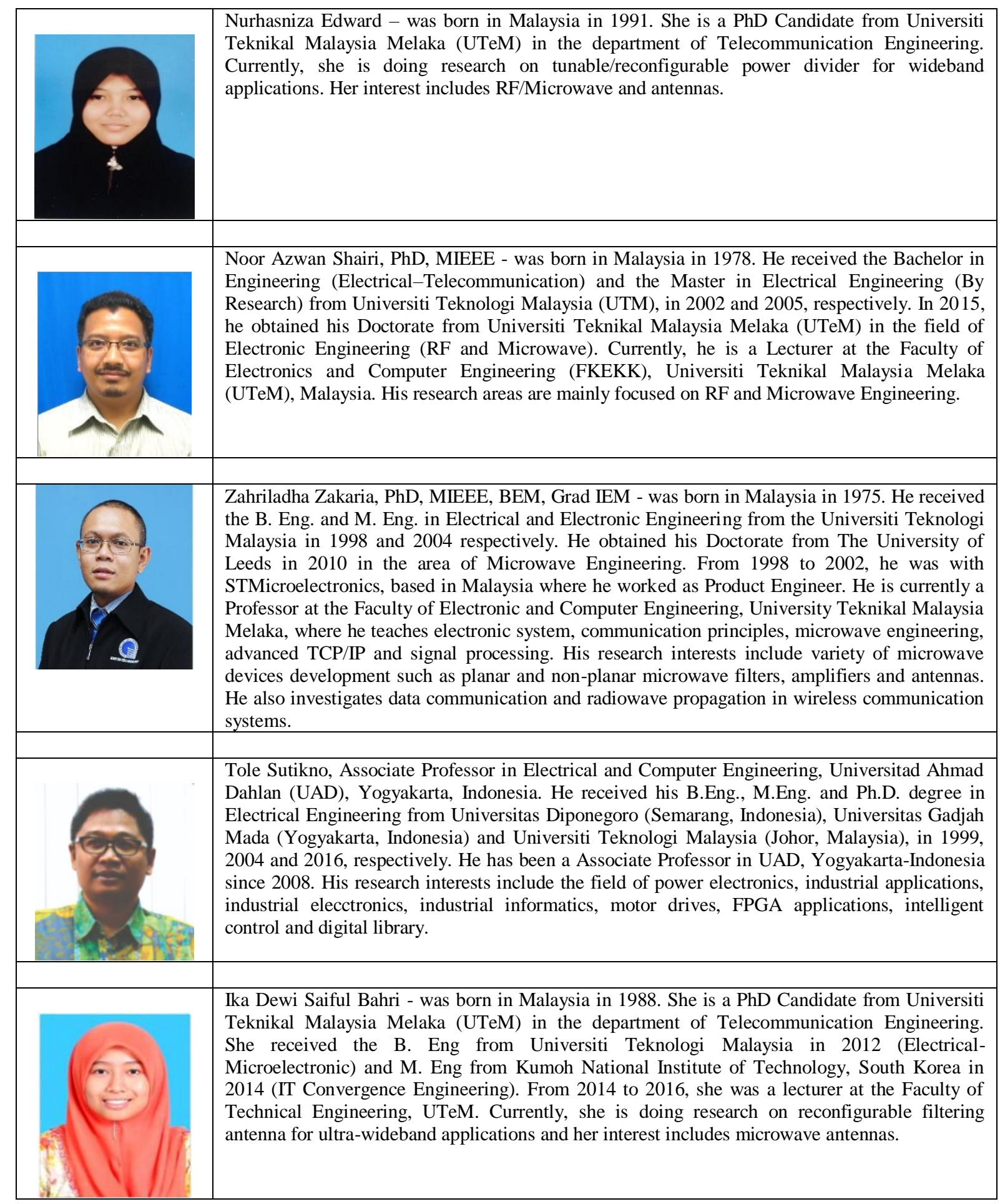

